\title{
CRITÉRIOS PARA UM PROCESSO DE FILIAÇÃO TEÓRICA E A NECESSIDADE DE UMA ABORDAGEM METODOLÓGICA QUALITATIVA $^{1}$
}

\author{
HenRiQue Gerson KoHL \\ Universidade Federal de Pernambuco / Brasil \\ profhenriquekohl@hotmail.com
}

\section{Resumo}

O artigo em questão busca contribuir para a compreensão da complexa conjuntura que abarca um objeto de pesquisa como condição indispensável de um processo de filiação teórica para ser possível (re)pensar a realidade do objeto. Desprovidos de uma teoria, caímos no risco de expressarmos considerações equivocadas da realidade investigada. A teoria deve ser provida de conceitos articulados e que refutem qualquer compreensão fragmentada da realidade. A adoção de uma teoria não significa adesão ao "teórico da moda", via recortes gratuitos de textos para figuração de pretextos desprovidos de contextos. Ela orienta o(a) pesquisador(a) para um constante e rigoroso (re)pensar da realidade para a construção de um conhecimento que seja socialmente relevante e cientificamente correto. Destarte, discutiremos nosso processo de filiação teórica fundamentando opções epistemológicas de uma pesquisa em andamento ao nível de doutoramento pela Linha de Pesquisa de Teoria e História da Educação do Programa de Pós-graduação em Educação da Universidade Federal de Pernambuco.

Palavras-chave: Pesquisa; Metodologia; Figuração; História Oral.

\section{CRITERIOS PARA UN PROCESO DE FILIACIÓN TEÓRICA Y LA NECESIDAD DE UN ABORDAJE METODOLÓGICO CUALITATIVO}

\section{Resumen}

Este artículo busca contribuir para la comprensión de la compleja coyuntura que abarca un objeto de investigación como condición de un proceso de filiación teórica para ser posible (re)pensar la realidad del objeto. Despojados de una teoría, caímos en el riesgo de expresar consideraciones equivocadas de la realidad investigada. La teoría debe ser sostenida de conceptos articulados y que refuten cualquier comprensión fragmentada de la realidad. La adopción de una teoría no significa adhesión al "teórico de la moda", por recortes gratuitos de textos para la figuración de pretextos despojados de contextos. Ella orienta al investigador hacia un (re)pensar de la realidad de la construcción de un conocimiento socialmente relevante y científicamente correcto. De esta manera, discutiremos nuestro proceso de filiación teórica fundamentando opciones epistemológicas de una investigación en curso al nivel de doctoramiento por la Línea de Investigación de Teoría e Historia de la Educación del Programa de Pos-graduación en Educación de la UFPE.

Palabras-clave: Investigación; Metodología; Figuración; Historia Oral.

\footnotetext{
${ }^{1} \mathrm{O}$ texto em questão é parte integrante de tese de doutoramento desenvolvida no Programa de Pós-Graduação em Educação da Universidade Federal de Pernambuco, pela Linha de Pesquisa de Teoria e História da Educação, orientada pelo Prof. Dr. José Luis Simões.
} 


\section{CRITERIA FOR A THEORETICAL DEPENDENCY PROCESS AND THE DEMAND OF A METHODOLOGICAL QUALITATIVE APPROACH}

\section{Abstract}

This article try to contribute for the comprehension of a complex conjuncture that encloses an object of research as a condition for a theoretical dependency process to be possible to (re)think the reality of the object. Deprived of a theory, we fall in the risk of expressing mistaken considerations about the investigated reality. The theory must be provided with well founded concepts and these ones must refute any fragmented understanding of reality. The adoption of a theory does not mean the adherence to the "theory of fashion" via free texts clipping to figuration pretexts without contexts. It leads the researcher to (re)think of the reality for the construction of knowledge socially relevant and scientifically correct. This way we will discuss our process of theoretical dependency establishing epistemological options for an ongoing research at the doctoral Line Research of the Theory and History of Education Post Graduate Program in Education at UFPE.

Key-words: Research; Methodology; Figuration; Oral History.

Mais uma roda de capoeira está sendo (re)organizada em solo pernambucano, mais especificamente na cidade de Recife. Muitos são os jogadores convidados para mais uma festa figurada a partir das tradições de uma manifestação da cultura afro-brasileira que, com seus cantos e encantos, estimula inquietações que se encontram ao pé do berimbau ${ }^{2}$ para um diálogo epistêmico ${ }^{3}$ regido pela rigorosidade científica.

Mills (1982), afirma que grandes pensadores não separam a pesquisa que realizam das suas vidas, em que existe o que caracteriza como um processo de fusão entre o pessoal e o intelectual. Defende que não existe o iniciar exato da pesquisa, ela já começa nas entrelinhas cuja gênese está na experiência de vida do pesquisador, núcleo vital para a figuração de todo o "produto intelectual" que anima o interior do pesquisador no sentido de mantê-lo desperto.

Nesse complexo processo de (re)construção do conhecimento, Mills (1982) nos chama atenção para a importância do(s) arquivo(s) do pesquisador acerca de temáticas inicialmente estimuladas pelo empírico. Arquivo(s) que movimentam nossa curiosidade epistemológica (Freire, 2002) para a tomada de decisões que possam favorecer a resolução da problemática da pesquisa via articulação analítica do empírico com determinada(s) corrente(s) de pensamento que oportunize um quadro teórico consistente para desvelar o objeto.

Para sustentação do arcabouço teórico - aqui chamado de "ritmo para o gingado das emoções" - temos as contribuições de Elias $^{4}(1980)$, sociólogo que critica a herança da sociologia por parte do

${ }^{2}$ No pé do(s) berimbau(s) que ritualisticamente inicia-se o jogo da capoeira.

${ }^{3}$ Do grego episteme, significa conhecimento.

${ }^{4}$ Norbert Elias nasceu em Breslau, Alemanha (22/12/1897) e faleceu em Amsterdã, na Holanda (01/08/1990). Com formação multidisciplinar, estudou Medicina, Filosofia e Psicologia. Permaneceu na Alemanha nazista até 
pensamento mítico e, também, das ciências naturais, que fragmentam a realidade através de conceitos que caracterizam o indivíduo como algo externo e numa posição de oposição ao mundo do qual é parte indissociável, no que chama de "modelo egocêntrico", permeado por conceitos que não foram herdados ao acaso, uma vez que, constituem respostas de segmentos cientes do que fazem e que respondem a determinados interesses.

Este modelo tradicional, segundo Elias (1980), nos apresenta os objetos de estudo como coisas estudadas por alguém. Trata-se de um ego específico cercado por estruturas sociais (família, escola, etc.) alicerçadas em um campo de conceitos reificantes que figuram uma espécie de receita clássica aplicável na realidade, que, estática, está além de nós.

Elias (1980) propõe transpor o paradigma em questão, revela o ser humano na condição de objeto menos conhecido pelos estudos sociológicos, em que a realidade é apresentada como algo externo ao indivíduo, ao eu, ao ego. Tal transposição é norteada pela ampla compreensão de nós como seres humanos figurados entre outros seres humanos que se relacionam dentro da realidade construída cotidianamente por cada um de nós.

Nesse sentido, nos oportuniza um olhar amplo, em que o conhecimento coletivo é construído com/na coletividade, em que assumimos a condição de "valências livres" que se relacionam das mais diversas maneiras formando o que define como "figurações" ou "teias de interdependências", nas quais nos encontramos ao termos a consciência de nossa "força" nessa dinâmica que dispensa polarizações entre indivíduos e a sociedade, o que Elias (1980: 16) define como "característica metafísica das estruturas sociais".

A complexidade figuracional discutida pelo autor evidencia que a interdependência entre figurações humanas supera paradigmas determinantes e indiferentes a complexidade social. As mudanças estão sempre presentes nas figurações, que, na condição de "valências livres", são desprovidas de uma lei explicativa primária. Para Elias (1980), movimentos figuracionais da sociedade são explicados via outros movimentos com notória interdependência e diferenciações de valências (re)ligadas de maneira indeterminada ao mesmo processo civilizatório.

É certo que Elias (1998) sugere um distanciamento da realidade no plano teórico-metodológico, porém sem uma posição de neutralidade em relação ao lócus pesquisado. Pelo contrário, fica mantida a relação de interdependência com o objeto, em que o nosso controle passa por marcos conceituais de um arcabouço teórico apropriado à compreensão das forças sociais de um determinado campo de

1933, quando foi para França e depois para a Inglaterra onde lecionou na Universidade de Leicester (1945-62). Posteriormente parte para trabalhar em Gana na África. Reconhecido tardiamente nos anos setenta do século $\mathrm{XX}$, publicou obras à luz da teoria do processo civilizador, de sua autoria. 
investigação. Forças de indivíduos sobre si próprios, sobre outros indivíduos e sobre o mundo que fazem parte.

Corrobora Souza (2009) ao alertar que “o laboratório das ciências naturais é um. O laboratório das ciências sociais é outro, logo, são ferramentas diferentes para serem apropriadas pelo pesquisador". Modelos desenvolvidos numa perspectiva egocêntrica das ciências naturais ou mágico-míticas, por exemplo, não ajudam na construção de um modelo teoricamente orientado para explicar aspectos da capoeira figurada na cidade do Recife nos anos 80 e 90 do século passado dentro do "gingado das emoções".

Gingado que compreende que qualquer diálogo entre as referências da capoeira ${ }^{6}$ e de outras áreas do conhecimento, exige do pesquisador a compreensão do processo de construção do conhecimento como resultante da articulação, do diálogo e da multirreferencialidade entre diferentes áreas do conhecimento.

Gingado que reconhece sua complexa interdependência social com a vida de referências da capoeira local, suas relações umas com as outras, suas relações com domínios oriundos da presente investigação cujo norte inicia-se a partir das seguintes questões:

- Como se figurava essa manifestação da cultura na cidade de Recife nos anos 80 e 90 do século XX?

- Como a prática da capoeira, enquanto possibilidade educativa não-formal propicia mudanças nas relações sociais entre seus representantes?

- Como se dá a construção do conhecimento na esfera da cultura local de práticas vividas com a capoeira?

- Há uma tríade de controle nas relações entre referências da capoeira recifense no período investigado?

Trabalhamos com a hipótese de que existiram mudanças no processo de formação do capoeira, geradas por processos educativos norteado por relações interdependentes entre figurações da capoeira da cidade de Recife e outras figurações (exs.: da capoeira de outros estados, não-formais de ensino, políticas, formais de ensino, etc.).

Processos presentes nas tradições que figuram essa manifestação da cultura, a qual se ensina e aprende-se jogando, lutando, vadiando, assistindo, escutando, entre outras ações interdependentes que

\footnotetext{
5 Ao ministrar aula referente à teoria de Norbert Elias na disciplina curricular de Pesquisa em Teoria e História da Educação III no dia 19/03/09 para o Programa de Pós-Graduação em Educação da Universidade Federal de Pernambuco.

${ }^{6}$ Grifo nosso. O destaque é dado por reconhecer aqui a inconteste importância das referências da capoeira como referências qualitativas dessa área do conhecimento. O valor de cada um é algo a ser sempre enfatizado em qualquer espaço em que sejam desenvolvidas reflexões acerca da capoeira.
} 
nos convidam a reflexão crítica sobre os caminhos históricos de processos civilizatórios que norteiam o controle das emoções da capoeira praticada por algumas de suas referências na cidade do Recife.

Com base na hipótese, materializam-se ideias para ser possível delimitar o seguinte problema de pesquisa: como a capoeira, como um fenômeno educativo não-formal, desenvolveu-se na cidade de Recife entre as décadas de 80 e 90 do século XX?

Sobre nosso marco temporal, reconhecemos que se trata de uma aproximação, pois não existem fronteiras temporais para relações dinâmicas como as materializadas na esfera educacional. $\mathrm{O}$ marco figura o objeto da pesquisa e demonstra adesão a uma tendência no campo da pesquisa em história da educação que busca realizar estudos comprometidos:

[...] com realidades mais circunscritas e com períodos mais curtos de tempo. Essa tendência tem possibilitado um aprofundamento de certos temas e uma complexificação na compreensão do passado de determinados fenômenos educativos que, anteriormente, eram visualizados apenas panoramicamente. Tem sido comum, por exemplo, no Brasil, que os pesquisadores de diversos estados procurem compreender determinados movimentos educacionais naquela realidade específica. Isso tem provocado uma verdadeira revisão daquilo que antes se tinha como verdade para todo o País e que, muitas vezes, só servia para compreender a realidade de São Paulo ou do antigo Distrito Federal, por exemplo. Muitas vezes, estudos realizados em alguns locais que, contemporaneamente, são mais fortes econômica e politicamente, generaliza(va)m as suas conclusões para a realidade do País em sua totalidade, desconsiderando-se as especificidades de cada realidade. O que muitas vezes ocorria, e que nos últimos anos tem-se transformado, é que, anacronicamente, tendia-se a considerar os estados ou cidades que são importantes na atualidade como igualmente importantes no passado. Generaliza(va)-se para o país o que é(era) específico somente para uma parte dele (Lopes, 2001: 42).

A relevância da problemática possui alicerce em três pilares. Um é referente à inexistência de trabalhos de pesquisa em educação sobre a capoeira ao nível de doutoramento no estado de Pernambuco. Outro, busca proporcionar maior visibilidade às mudanças geradas na formação do capoeira do Recife e suas contribuições na expansão da capoeira para outras figurações. Outro, contribuir na superação da tendência de pesquisadores e/ou programas de fomento à pesquisa em excluírem aquela temática que não é homogênea na tradição acadêmica.

Imerso nesta problemática a pesquisa vai sendo definida, permitindo a passagem do objetivo o qual assim é estabelecido: investigar e identificar as influências da capoeira para construção de práticas educacionais na cidade de Recife, entre as décadas de 80 e 90 do século XX.

No referente aos objetivos específicos, busca-se compreender o(s) tipo(s) de relações sociais entre a capoeira recifense e outras valências sociais e analisar como se deu o processo civilizatório de algumas referências reconhecidas por alguns coletivos representativos da capoeira local. 
Importante destacar que a opção da pesquisa pelo recorte histórico em questão considera o período de início na prática da capoeira por parte de referências que são responsáveis pela expansão da capoeira recifense aos níveis local, municipal, estadual, regional, nacional e internacional.

E é nesse sentido que a pesquisa é delineada, objetivando uma maior compreensão desse período histórico com empenho na "experiência controlada" (Mills, 1982) e com a base epistêmica de Norbert Elias que contribui com categorias de análise provenientes do seu arcabouço teórico.

Análise que figura uma possível leitura da realidade, a qual está aberta para outras (re)leituras críticas doutros que desejem contribuir para o "gingado das emoções". Leitura que não deseja colocar as referências da capoeira recifense à margem dos méritos das descobertas a serem socializadas pela pesquisa. Ao contrário, antecipamos compreensão de que tais referências também são autoras do conhecimento aqui desenvolvido coletivamente COM outras referências e não PARA elas.

Atentos à dinâmica das figurações sociais, é possível ter a leitura de que nenhum movimento ocorre desprovido da dimensão educacional que permeia toda a sociedade. Para além dos níveis formais de escolarização existentes, notórias as maneiras que cada figuração educa e educa-se em relação a outras figurações. Destarte, corroboramos com Lopes (2001), quando diz que devemos pensar não na história e sim nas histórias da educação.

Reconhecer tais histórias significa buscar uma curiosidade epistêmica (Freire, 2002) além das relevantes temáticas pesquisadas tradicionalmente (exs.: escola, avaliação, etc.) e que poderá contribuir para o melhor entendimento doutros relevantes processos educativos.

[...] a educação nunca se restringiu à escola. Práticas educativas têm ocorrido, ao longo do tempo, fora dessa instituição e, às vezes, com maior força do que se considera, principalmente para certos grupos sociais e em determinadas épocas. A cidade, o trabalho, o lazer, os movimentos sociais, a família, a Igreja foram, e continuam sendo, poderosas forças nos processos de inserção de homens e mulheres em mundos culturais específicos (Lopes, 2001: 24).

Pensar processos ocorridos no contexto da capoeira de Recife implica em encontros com outros atores para tentarmos desvelar os quês e os porquês de acontecimentos que são perpetuados pela oralidade dos que constituem uma capoeira que dispensa relações lineares entre passado, presente e futuro; que busca espaço numa pesquisa que almeja fazer uma leitura do que vem acontecendo e não o que deveria ter acontecido, que considere suas descontinuidades e contradições históricas.

\section{Condições e estratégias metodológicas}

Numa abordagem metodológica qualitativa, no campo da história da educação, delimitar este estudo consiste em optar por caminhos que nos coloquem na direção do objeto para, então, dialogar a 
luz de pressupostos favoráveis à liberdade de criação investigativa, que respeite as identidades culturais de cada um e estimule a liberdade de criação dos atores.

Nessa perspectiva, aqui compreendida no seu sentido etimológico de enraizar a reflexão, olhar além de um cenário, pensamos que uma pesquisa deve estar comprometida com a procura, análise, compreensão e socialização junto à sociedade, visando a uma epistemologia referente à memória coletiva dos atores da pesquisa.

Para compreendermos a complexa conjuntura que abarca um objeto de pesquisa, é condição indispensável um consistente processo de filiação teórica para ser possível (re)pensarmos a realidade do objeto. Desprovidos de uma teoria, caímos no risco de expressarmos considerações equivocadas da realidade investigada.

Essa teoria deve ser provida de conceitos articulados e que refutem qualquer compreensão fragmentada da realidade. A adoção de uma teoria não significa adesão ao "teórico da moda", via recortes gratuitos de textos para figuração de pretextos desprovidos de contextos. Ela orienta o pesquisador para um constante e rigoroso (re)pensar da realidade para a construção de um conhecimento que seja socialmente relevante e cientificamente correto.

Destarte, nosso processo de filiação teórica junto à teoria eliasiana apresentada brevemente no tópico anterior, figura-se a partir do final do ano de 2008, durante discussões ainda insipientes realizadas entre membros do Laboratório de Sociologia do Esporte-LASEPE/DEF/CCS/UFPE e orientados pelo líder do grupo de pesquisa, o Prof. Dr. Edilson Fernandes de Souza.

As discussões eram norteadas por meio do estudo de obras escritas pelo pesquisador Norbert Elias. A leitura inicial foi orientada a partir do prefácio e da introdução da obra de Elias e Dunning (1992) intitulada "A Busca da Excitação". Isso favoreceu uma aproximação inicial com um autor que demonstrou densidade epistemológica e relevância para as temáticas do coletivo. Destacamos a questão referente ao controle das emoções?.

Um ponto em comum entre os pesquisadores era a necessidade de aprofundamento não só da leitura em questão, como de outras produções eliasianas reveladoras de marcos teóricos importantes para figurar à luz teórica de estudos que buscavam "excitação teórica" via uma abordagem qualitativa.

No primeiro semestre do ano de 2009, participamos da disciplina intitulada "Pesquisa em Teoria e História da Educação III(60hs)". Disciplina eletiva, sob responsabilidade da Linha de Pesquisa de Teoria e História da Educação, ministrada pelo Prof. Dr. Edilson Fernandes de Souza e pelo Prof. Dr. José Luis Simões.

\footnotetext{
${ }^{7}$ Em Elias (1995), constatamos que as sociedades estudadas possuem meios para alívio de tensões oriundas de um expressivo esforço de autocontrole emocional, em especial a violência. $\mathrm{O}$ autor cita alguns esportes como exemplos para tais alívios.
} 
Durante o desenvolvimento da disciplina, foi possível discutir junto com os docentes e discentes, limites e possibilidades de nossas inquietações epistêmicas. Sobreleva dizer que a dinâmica da disciplina, através de um rodízio de leituras coletivas dos projetos de pesquisa com as mais variadas temáticas, ajudou significativamente no desenvolvimento das intencionalidades de pesquisa.

Os presentes, na maioria das vezes, faziam leitura minuciosa de todo o projeto de pesquisa do colega para, no dia coletivamente acordado, tecerem suas importantes considerações. Críticas motivadas por um exercício cotidiano de trocas acadêmicas para crescimento do grupo. Após as contribuições discentes, os docentes articulavam as colocações e apresentavam as suas inferências. Para o autor, tratava-se de um momento de inconteste importância em virtude da multirreferencialidade epistêmica acumulada pelos vieses das experiências do coletivo. Socializadas as contribuições para a intencionalidade de pesquisa do autor, ficava o indicativo de diálogo com o orientador, ou possível orientador, no sentido de respeito à autonomia intelectual de cada um.

No nosso caso, foi possível atestar expressivo aproveitamento das colocações apresentadas, o que motivou, no segundo semestre do ano de 2009, inscrição noutra disciplina pelo mesmo programa. Dada a dinâmica presenciada anteriormente, optamos pela disciplina "Pesquisa em Teoria e História da Educação II (60hs)". Disciplina eletiva, sob responsabilidade da Linha de Pesquisa de Teoria e História da Educação, ministrada pelo Prof. Dr. Edilson Fernandes de Souza e pelo Prof. Dr. José Luis Simões.

O viés da disciplina foi o mesmo da frequentada anteriormente, porém, em virtude de nova oportunidade de apresentação para apreciação coletiva, novas contribuições foram acolhidas, favorecendo maior consistência para figuração da intencionalidade de pesquisa. Esse acolhimento resultou em motivação para fazer a seleção para o doutorado do referido programa no ano de 2010. Com êxito no processo seletivo, atualmente desenvolvemos estudo no formato de tese. Vitória que reafirma a importância de ampliarmos a nossa capacidade auricular, entre outras também importantes no processo de formação do pesquisador.

Escutar é obviamente algo que vai mais além da possibilidade auditiva de cada um. [...] significa a disponibilidade permanente por parte do sujeito que escuta para a abertura à fala do outro, ao gesto do outro, às diferenças do outro. Isto não quer dizer, evidentemente, que escutar exija de quem realmente escuta sua redução ao outro que fala. Isto não seria escuta, mas auto-anulação. A verdadeira escuta não diminui em mim, em nada, a capacidade de exercer o direito de discordar, de me opor, de me posicionar. Pelo contrário, é escutando bem que me preparo para melhor me colocar ou melhor me situar do ponto de vista das idéias. Como sujeito que se dá ao discurso do outro, sem preconceitos, o bom escutador fala e diz de sua posição com desenvoltura. Precisamente porque escuta, sua fala discordante, em sendo afirmativa, porque escuta, jamais é autoritária. (Freire, 2002:135). 
Regularmente matriculados, começamos a refletir com maior imersão teórica sobre a epistemologia ofertada pela obra de Norbert Elias e sua relação com o nosso objeto de pesquisa no campo da história da educação. Elias (1998) chama atenção para o fato da necessidade de apresentarmos nossa leitura de mundo a partir do que descobrimos como cientistas e não como gostaríamos que o mundo fosse. Chama atenção para que sempre utilizemos a base empírica e teórica ao analisarmos o objeto de pesquisa. Sugere, mesmo reconhecendo as complexas dificuldades, um afastamento do objeto para materialização de novas perspectivas.

$\mathrm{O}$ autor refuta qualquer dicotomia, "pesquisador e objeto de pesquisa" por exemplo, permitindo uma perspectiva global de abordagem. Abordagem que permite uma relação de envolvimento com o objeto. Considera o humano como ser relacional em cadeias específicas de interdependências diversificadas, mutáveis, empiricamente evidentes e em movimentos diversos. Movimentos que não são antagônicos, polarizados ou antíteses, ao contrário, são complementares. Os movimentos são de figurações redimensionadas continuamente e imprevisíveis, como explica Elias (1994), fazendo analogia a uma dança de salão, em que as pessoas dançam de maneiras a figurarem uma teia complexa de interdependências.

Dessa maneira, lembramos da roda da capoeira, a qual, com sua gestualidade, ritualística e musicalidade, ganha expressões interdependentes a cada figuração social materializada nas praças, ruas, escolas, universidades e outros lócus.

Figurações sociais providas de saberes desenvolvidos processualmente ao longo do tempo nas estruturas da sociedade, oriundas de processos interativos e históricos civilizacionais com funções mutáveis ao longo dos múltiplos processos de desenvolvimento nos quais figuram as ações humanas ao mesmo tempo em que modulam uma sociedade em que:

[...] cultura não é um lugar subjetivo, ela abrange uma objetividade com a espessura que tem a vida, por onde passa o econômico, o político, o religioso, o simbólico e o imaginário. Ela é o lócus onde se articulam os conflitos e as concessões, as tradições e as mudanças e onde tudo ganha sentido, ou sentidos, uma vez que nunca há apenas um significado (Minayo, 2004:15).

Outra relevante questão, que acreditamos ser importante, versa sobre a questão de a pesquisa possuir norte quantitativo ou qualitativo. Acreditamos na interdependência figurada pela questão qualidade-quantidade no que se refere às relações sociais. Qualquer dicotomia só poderá contribuir para uma fragmentação do conhecimento científico existente nos meandros das relações que orientam as ações humanas. Polarizações do tipo racionalidade e sensibilidade, sagrado e profano, exterioridade e interioridade, bom e mau, corpo e mente, teoria e prática, entre outras, devem ser superadas por um 
esforço de interpretação autônoma a luz de teoria que oriente nossa prática. Concordamos com Minayo

(2004: 12) quando afirma que uma opção metodológica qualitativa não significa:

[...] uma alternativa ideológica às abordagens quantitativas, mas a aprofundar o caráter do social e as dificuldades de construção do conhecimento que o apreendem de forma parcial e inacabada. As diferentes teorias que abrangem (cada uma delas) aspectos particulares e relegam outros, nos revelam o inevitável imbricamento entre conhecimento e interesse, entre condições históricas e avanço das ciências, entre identidade do pesquisador e seu objeto, e a necessidade indiscutível da crítica interna e externa na objetivação do saber.

Uma opção metodológica não trata de aplicações de procedimentos metodológicos e sim de uma construção rigorosa que começa na delimitação do objeto de pesquisa a partir do marco teórico. Importante lembrarmos que a metodologia não conhece o nosso objeto de pesquisa.

Outrossim, tão importante quanto ter domínio dos conhecimentos acumulados historicamente, é fundamental ter a plena consciência da possibilidade do pesquisador construir conhecimento(s) que ainda não existe(am).

Todo o percurso da pesquisa deve ser criteriosamente justificado no sentido de elucidar os motivos de cada escolha. Destarte, a materialização das justificativas apresentadas ao longo das laudas que figuram uma produção científica só é possível se tivermos a clareza dos objetivos. Importante termos uma construção epistemológica prévia para um constante movimento ético de reflexão norteado por categorias empíricas e analíticas.

[...] seria incompreensível se a consciência de minha presença no mundo não significasse já a impossibilidade de minha ausência na construção da própria presença. Como presença consciente no mundo não posso escapar à responsabilidade ética no meu mover-me no mundo. Se sou puro produto da determinação genética ou cultural ou de classe, sou irresponsável pelo que faço no mover-me no mundo e se careço de responsabilidade não posso falar em ética. Isto não significa negar os condicionamentos genéticos, culturais, sociais a que estamos submetidos. Significa reconhecer que somos seres condicionados, mas não determinados. Reconhecer que a História é tempo de possibilidade e não de determinismo, que o futuro, permita-se me reiterar, é problemático e não inexorável. (Freire, 2002: 20-21).

No doutorado nos deparamos com a exigência de uma abordagem recriada a partir de nossa autonomia intelectual e de filiações ${ }^{8}$ teórico-metodológicas que dialoguem criteriosamente com o objeto

\footnotetext{
${ }^{8}$ O presente tópico foi desenvolvido a partir de significativas contribuições do Prof. Dr. Janssem Felipe da Silva durante aula que ministrou na condição de docente convidado na disciplina intitulada "Seminário de Teoria e Metodologia da Pesquisa em Educação II”, na quarta-feira (08 às 12h) do dia 27/10/2010. Disciplina obrigatória para o curso do doutorado e sob responsabilidade do Programa de Pós-Graduação em Educação da Universidade Federal de Pernambuco, ministrada pelas docentes Dra Eliana Albuquerque e Dra. Maria da Conceição Carrilho.
} 
de pesquisa. Os processos de filiações oportunizam a delimitação de uma territorialidade em que abordarmos o objeto. A delimitação do objeto é fundamental para o desenvolvimento da pesquisa. Quanto mais criteriosa a circunscrição do objeto, mais claro será o processo de construção dos objetivos. A metodologia não é algo à parte. Ela figura uma interdependência com os objetivos da pesquisa, com a luz teórica escolhida para um processo de análise norteado pelos objetivos.

Muitas são as perguntas que devemos responder durante o processo de constituição de uma tese. Pensar qual o paradigma, concepção ou constituição epistemológica que orienta a pesquisa. Qual é a nossa concepção de ciência e no que tal concepção ajuda na compreensão do objeto? Até onde pode ir nossa condição teórica? Quais os limites e as possibilidades do nosso tempo de produção? Quais os limites e as possibilidades do tempo institucional exigido para término da pesquisa?

Essas são questões primordiais para orientação do percurso metodológico apresentado para a crítica acadêmica, além de favorecer a relação do pesquisador com o objeto em complexas decisões da pesquisa, os critérios de escolha, por exemplo.

Para além de explicitarmos o viés qualitativo da pesquisa, é de inconteste importância demonstrar todo percurso duma produção reveladora dos porquês para além do que ela é. Ou seja, para além de conceituar os conceitos, justificá-los cientificamente. Justificativa possível pelo viés de uma abordagem metodológica favorável a constatação, interpretação, compreensão e explicação da complexa relação de interdependência entre abordagem metodológica, objeto, objetivo geral, objetivos específicos e procedimentos técnicos que figuram a pesquisa.

É preciso que essa oportunize uma segurança necessária para o pesquisador imergir na problemática que desenvolve. Do contrário, existe o perigo de lacunas epistemológicas. Assim, a partir de uma filiação à abordagem eliasiana, guiados por uma interdependência entre vieses qualitativos e quantitativos, pensamos em princípios e conceitos que organizam o conhecimento selecionado via problematização do universo empírico em questão, onde figura o objeto de pesquisa e que está sempre articulado à teoria.

\section{Contribuições da história oral}

Levados pela oportunidade de colaborarmos de alguma forma para a história da educação é que fomos motivados pela possibilidade de materializar uma contribuição significativa para a história de algumas referências da capoeira de Recife-PE, em especial em relação à preservação de parte da memória dos mestres que contribuíram para formação de muitas gerações de uma manifestação ligada a referências de outros estados brasileiros e de outros países.

Desta maneira, realizamos a opção pelas contribuições da história oral (Thompson, 1992; Montenegro, 2007) enquanto recurso que surge numa determinada realidade, mais especificamente em 
coletivos da capoeira recifense, exigindo rigor para sua adoção numa pesquisa permeada por categorias que surgem a partir das narrativas dos autores. Não desejamos desrespeitar uma tradição de pesquisar com rigor necessário enquanto condição para legitimação das descobertas. Assim, sobreleva-nos apresentar algumas reflexões acerca da compreensão que temos sobre o presente recurso metodológico.

Destacamos que segmentos sociais compostos por indivíduos geralmente excluídos de todo um processo social regido pelo capitalismo, ganham, também, no viés da história oral, a oportunidade de expressar suas visões e mostrar as figurações que integram. Podemos afirmar que a narrativa é um importante elemento da história oral. Não é o sujeito em si que constitui objeto de estudo e sim seus relatos de experiências oportunizados por uma série de particularidades interdependentes que figuram um determinado objeto de estudo (Thompson, 1992; Montenegro, 2007).

Dentre as particularidades, a subjetividade por parte do narrador e do pesquisador ganha importante relevância. Dados figurados a partir de contradições, sentidos, signos, significados, emoções, entre outros, constituem a estética de uma metodologia cuja beleza está no esforço teórico para constatar, interpretar, compreender e explicar dados de uma realidade dinâmica.

Optamos pela perspectiva de depoimentos orais em que o narrador socializa informações presenciadas por ele. Temos consciência da impossibilidade de rememorar toda a realidade vivida pelo narrador, quando buscamos dados factuais através de referências diretas em relação ao objeto da pesquisa (Lang, 1996).

No referente às fontes orais, realizaremos coleta de depoimentos dos atores que constituem o período histórico contemplado pela pesquisa e que são referências na maior parte ${ }^{9}$ dos coletivos da capoeira recifense. Eles contribuirão com uma maior compreensão acerca do contexto educacional que marcou e marca gerações da capoeira recifense.

Referente ao processo de coleta de dados, optamos pela entrevista para favorecer a compreensão mais significativa das ações dos entrevistados, quando buscamos dar conta do desafio de coletar atentamente a riqueza de cada depoimento. Acreditamos que essa riqueza não está na extensão das falas e sim no conteúdo que representa o desafio no referente ao seu desvelar criterioso (Lang, 1996). Em meio a questionamentos, seguimos abertos durante cada etapa da pesquisa, em que educamos nossa capacidade auricular via o arcabouço teórico eliasiano, o qual favorece a compreensão do que deve ou não ser abstraído durante coleta e análise daquilo que seja relevante para o trabalho.

Objetividade e subjetividade são ritmos que se completam na busca contínua pela reconstituição do objeto da pesquisa. Desta maneira, após coleta dos dados, rigorosas transcrições, fichamentos

\footnotetext{
${ }_{9}$ Quando afirmamos que são reconhecidos na maior parte dos coletivos existentes, estamos reconhecendo as contradições que existem entre diferentes agrupamentos com diferentes processos formativos. Logo, algumas figurações não reconhecem o processo de formação de outras figurações.
} 
detalhados, releituras dos fichamentos, novas escutas das gravações, lembranças de cada momento junto com entrevistados e de reflexões balizadas pela teoria, temos a possibilidade de desvelar o objeto da pesquisa.

Questões como os critérios para a escolha dos atores que guardam determinada memória, dos questionamentos a serem feitos, das possíveis lacunas em cada fala, dos questionamentos complementares realizados, da organização dos dados, o modo de analisar as relações sociais que permeiam o objeto, os recortes a serem realizados, entre outras, serão aspectos explorados noutro artigo.

Procedimento adotado por pesquisas em história da educação, a história oral proporciona ao pesquisador recorrer aos documentos orais como elementos significativos da história. Thompson (1992) contribui ao definir a história oral como prática social favorável a possibilidades de mudanças no enfoque histórico e reveladora de caminhos que nos levam ao encontro de novas possibilidades investigativas.

No campo que pretendemos pesquisar, as fontes estão vivas, o que favorece rico material para análise. São lideranças das figurações representativas da capoeira da cidade de Recife.

Durante os encontros para orientação pensamos todo o processo de entrevista no sentido de nos tornarmos "bom ouvinte, e o informante, um auxiliar ativo" (Thompson, 1992: 25). Outra contribuição do autor supracitado vem no sentido de despertarmos a memória do entrevistado, a qual depende de aspectos significativos para favorecer suas lembranças.

Um caminho pensado foi o da realização de visitas prévias aos entrevistados e apresentação de forma elucidativa das intencionalidades da pesquisa e seus possíveis desdobramentos, e, também, o de anteciparmos o reconhecimento deles como atores da pesquisa. Muitas referências da capoeira que colaboraram em pesquisas de diversas naturezas reclamam que poucas vezes recebem informações suficientes e/ou retorno acerca dos resultados, o que gera compreensível dificuldade para pesquisas futuras.

Ainda adotando as contribuições de Thompson (1992), procuraremos elaborar as questões de forma simples, de fácil compreensão e que respondam as inquietações acadêmicas que norteiam a pesquisa. O ritmo adotado para o jogo, referente à coleta dos depoimentos dos atores, contempla os seguintes pontos: a) o contexto educacional da formação da capoeira de Recife; b) a relação dos moradores não praticantes de capoeira com essa manifestação da cultura; c) a relação do contexto educacional com essa manifestação cultural; d) o trabalho dos grupos de capoeira existentes; f) que instituições educacionais da cidade abriram espaços e/ou contribuíram de outras formas significativas para o desenvolvimento dessa manifestação. 
As respostas serão transcritas com cautela, pois, conforme Thompson (1992: 337), o presente recurso metodológico "devolve a história às pessoas em suas próprias palavras. E ao dar-lhes um passado, ajuda-as também a caminhar para um futuro construído por elas mesmas."

A análise das fontes orais contribui no sentido de ampliação das possibilidades de esclarecimento dos episódios vividos, devido à quantidade e qualidade das informações coletadas, elucidando questões que provavelmente outros tipos de registros não dariam conta.

Em relação ao processo de categorização das fontes, importante momento metodológico, a filiação teórica e a figuração do problema são de suma importância para figuração de relações analisadas à luz da teoria adotada. Sem falar que o processo de categorização evita uma transcrição integral que ajude na elucidação do objeto.

Outro aspecto importante exigido do pesquisador é o desenvolvimento de sua capacidade criativa para figuração de estratégias a fim de lidar com as intempéries da pesquisa em tempo hábil. Importante destacar que temos absoluta consciência da necessidade de dialogarmos com outras fontes de pesquisa, as quais possam, junto à história oral, figurar qualitativamente o objeto de pesquisa. Destarte, outros instrumentos adotados enriquecem a pesquisa que procura possibilidades de articulação na análise documental, iconográfica e outros recursos que dialogam com as fontes.

Com a ampliação de temáticas contempladas pelo campo de história da educação, é possível constatar uma crescente ampliação dos tipos de fontes adotadas para as pesquisas. Também notório o rigor e o cuidado em relação às perspectivas de problematizações, categorizações e análises das fontes.

Voltamos a destacar a condição auricular do pesquisador, a qual ganha espaço pelo viés da história oral que, norteada pela figuração de uma problemática que possui nenhuma ou pouca documentação, adota a fala direcionada pelo problema como fonte.

Vale a pena frisar, a "história" oral não deve ser considerada o próprio produto da pesquisa histórica, mas submetida às mesmas exigências do tratamento requerido por outras fontes documentais e inerentes ao trabalho historiográfico. (Lopes, 2001: 90).

Fala que exige do pesquisador uma relativização em relação às falas, pois a memória é seletiva e passível de mudanças ao longo do tempo. Sem contar que existe o risco de os colaboradores falarem o que imaginam que devem falar e não o que ocorreu. Desta maneira, contradições que surgem por entre as múltiplas verdades que possam perpassar o objeto nos exigem inconteste responsabilidade nas ações que figuram toda a pesquisa.

Antecipamos termos a consciência da questão ética referente ao respeito a cada ator da pesquisa, os quais, além de figurarem núcleo vital do trabalho, devem ter o retorno do trabalho pelo 
qual também são responsáveis. Ninguém pesquisa sozinho, assim como nenhuma roda de capoeira pode ser realizada sem todo um coletivo articulado entre si.

A liberdade de expressão de cada ator, em qualquer que seja a pesquisa, deve ser respeitada ao ritmo das suas razões e emoções. Um jogo de capoeira consiste numa constante troca entre os jogadores, logo, tal troca, na pesquisa, é expressa desde o aceite do entrevistado pelo entrevistador para o "gingado das emoções", em que perguntas e respostas figuram intencionalidades presentes em cada movimento de ambos os lados.

Esses lados que não são os únicos participantes do diálogo em questão, pois além das referências teóricas adotadas, temos de prestar conta, de forma rigorosa e cientificamente correta, à comunidade científica que recebe para apreciação uma tese desenvolvida em âmbito público federal.

\section{Considerações provisórias}

Temos aqui materializado um objeto demarcado por um marco temporal figurado entre o início da década de oitenta e final da década de noventa do século passado. Marco que não é estático, ao contrário, representa processos em movimentos que exigem a construção de modelos que expressem processos teóricos articuladores de acontecimentos explicados em termos processuais.

Assim, ritmados por um jogo criterioso à luz da teoria eliasiana, buscamos na temática da capoeira recifense um campo de pesquisa, em que a singularidade de cada um tem espaço e valor na roda de descobertas. Nesse sentido, podem-se ampliar as reflexões acerca dos caminhos até aqui discutidos a partir da obra do professor de capoeira Douglas Rodrigues Pinheiro de Araújo ${ }^{10}$, compositor de uma música que nos toca ao longo da trajetória que figura a pesquisa.

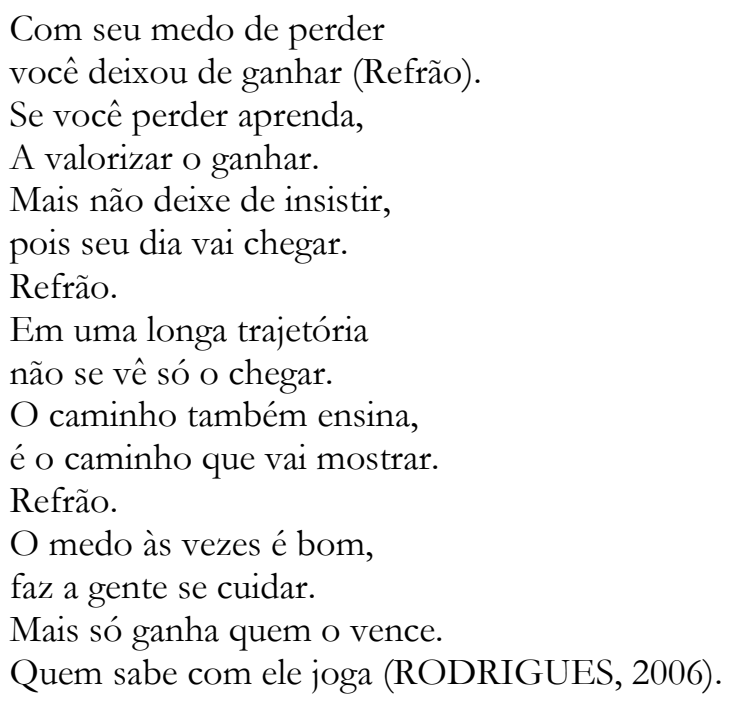

10 Referência do estado de Pernambuco, membro do Grupo Capoeira Nagô. Reconhecido nacional e internacionalmente como um dos melhores cantadores e compositores de músicas de capoeira. 


\section{Referências}

APÊNDICE: do artesanato intelectual. In: MILLS, C. Wright. A imaginação sociológica. 6. ed. Rio de janeiro: Zahar Editores, 1982. p. 211-243.

ELIAS, Norbert. Introdução à sociologia. Braga, Portugal: Pax, 1980.

e DUNNING, Eric. A busca da excitação. In: ELIAS, Norbert. A busca da excitação.

Lisboa: Difusão Editorial Lda. 1992.

A sociedade dos indivíduos. Rio de Janeiro: Jorge Zahar, 1994.

Envolvimento e alienação. Rio de Janeiro: Bertrand Brasil, 1998.

FREIRE, Paulo. Pedagogia da autonomia: saberes necessários para à prática educativa. 23. ed. São Paulo: Paz e Terra, 2002.

LANG, Alice Beatriz da Silva Gordo. História Oral: Muitas Dúvidas, Poucas Certezas e Uma Proposta. In: MEIHY, José Carlos Sebe (Org.). (Re) Introduzindo História Oral no Brasil. Série Eventos. São Paulo: Universidade de São Paulo, 1996.

LOPES, Eliane Maria Teixeira; GALVÃO, Ana Maria de Oliveira. História da educação. Rio de Janeiro: DP\&A, 2001.

MINAYO, Maria Cecília de Souza. O desafio do conhecimento: pesquisa qualitativa em saúde. 8. ed. São Paulo: Hucitec, 2004.

MONTENEGRO, Antonio Torres. História oral e memória? A cultura popular revisitada. 6. Ed. São Paulo: Contexto, 2007.

RODRIGUES, Douglas. Medo de perder. Intérpretes: Douglas. In: PEQUINÊS, C. Mestre. Capoeiranagô. Goiânia: Gravação Independente, 2006. 1 CD. Faixa 9.

SOUZA, Edílson Fernandes. Entre o Fogo e o Vento: As práticas de Batuques e o controle das Emoções. Recife: Editora Universitária da UFPE, 2001.

SOUZA, Edilson Fernandes; SIMÕES, José Luís; LUCENA, Ricardo de Figueiredo (Orgs.). Escritos a partir de Norbert Elias. Recife: Editora Universitária da UFPE, 2009.

THOMPSON, Paul. A voz do passado: história oral. Rio de Janeiro: Paz e Terra, 1992. 